\title{
On the Inherent Complexity of Language: The Interaction of Numerals and Incorporation*
}

\author{
John Stonham \\ Pukyong National University
}

\begin{abstract}
The Nuuchahnulth language of Vancouver Island is a morphologically complex language which makes extensive use of both polysynthesis and incorporation. Furthermore, it exhibits a typologically unusual number system which may best be described as split decimal/ vigesimal. However, the most fascinating aspect of these properties is the complex interaction that takes place when numbers are incorporated into the verb. This paper will examine this interaction and the structures and processes that are involved in its realization. The consequences of this interaction provide us with an example of a complex linguistic system that extends to the limits our conception of language processing and learnability and the models we propose to deal with it.
\end{abstract}

* Thanks to Eun-Sook Kim and Steve Matthews for comments on earlier versions of this paper and to the anonymous reviewers for their helpful comments.

Nuuchahnulth is also known in the literature as Nootka. Data for this paper are drawn mainly from the unpublished fieldnotes of Edward Sapir (Sapir Ms.) gathered in the early part of the 20th C. when the language was viable. Published versions of some of this material appear in Sapir \& Swadesh $(1939,1955)$. 
Keywords: Complex numerals, incorporation, Nuuchahnulth, coordination

The Nuuchahnulth language is spoken on the west coast of Vancouver Island in the Pacific Northwest of America. It is presently spoken by only a small number of elderly individuals, mainly over the age of seventy: in other words, it is in an extreme state of language endangerment. It exhibits a number of interesting properties in different areas of the grammar, but the phenomena to be examined here are perhaps the most complex and the most interesting. They involve the interaction between the verb and its object, in particular when that object contains a numeral. In such cases, the numeral, or in the most extreme case, a part of a complex numeral, appears combined with the verb, while the remainder of the object appears where it would normally occur in the sentence.

This kind of phenomenon challenges our understanding of how languages work and how they can be learned and compels us to accept that long-distance dependencies between elements within the sentence are a very real possibility in language and that our theories must be prepared to deal with such contingencies when they arise.

In what follows, I will first examine the basics of polysynthesis and incorporation in Nuuchahnulth, followed by a discussion of the numeral system, including the use of classifiers, and then an examination of the internal structure of the quantifier and noun phrases. I then move on to examine the focus of the paper, the incorporation of numerals into the verb and the extent to which this may apply.

\section{Polysynthesis in Nuuchahnulth}

Nuuchahnulth $^{1}$ words always involve a single root morpheme,

\footnotetext{
${ }^{1}$ For a detailed discussion of the phonetics and phonology of Nuuchahnulth, see
} 
which acts as the core or nucleus of the word. The root may combine with reduplicative prefixes, both derivational and inflectional suffixes, and with a small number of infixes. Wordinternal compounding is not permitted (but see Stonham 2004 on phrase-level compounding). The language makes extensive use of suffixation in both creating new lexemes, as well as in marking inflectional categories in the grammar and the morphological structure is best described as polysynthetic (Baker 1996, Gerdts 1988). Clitics are also found following the first element of a phrase, i.e., in second position. The basic structure of the word is as in (1).

\section{(1) REDUPLICATION- $\underline{\text { ROOT }}$ - DERIVATIONAL SUFFIXES - INFLECTIONAL SUFFIXES $=$ CLITICS}

A word may consist of only the root, or may be built up in various ways. Certain suffixes require a concomitant reduplication of some part of the beginning of the root. Inflectional suffixes are most evident with verbs, which usually appear initially in the sentence. Examples of various possibilities appear in (2) below.

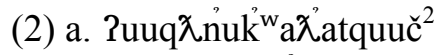

$$
\begin{aligned}
& \text { Pu-'aqג -nuk -'a } \chi \quad \text {-'at -quuč } \\
& \text { REF -inside-in hand -NOW -SW -3.CND }
\end{aligned}
$$

Stonham (1999). For more information regarding its complex morphology, see Kim (2003), Stonham (2004).

${ }^{2}$ Data for this paper are transcribed in a modified Americanist format. Principal divergences from the IPA include: $\breve{\mathrm{s}}=\int, \breve{c}=\mathrm{t} \int, \chi=\mathrm{t} \mathrm{\text { }}$. Abbreviations employed in this paper include the following: [R] reduplicated, ABS absolutive mood, CAUS causative, CLS classifier, CND conditional mood, DEF definite, DIM diminutive, DIST distributive, DUR durative aspect, FUT future tense, IND indicative mood, ITER iterative aspect, LOC locative, MOM/M momentaneous aspect, NOM nominalizer, NOW contemporaneous, P plural, POSS possessive, QUOT quotative, REL relative, S singular, SUB subordinate mood, SUF suffix-triggered reduplication, SW switch reference. 
'If one is holding a stick.'

b. hiniicsk ${ }^{\mathrm{w}}$ ispið ikqa

hina-iics - $\mathrm{k}^{\mathrm{w}}$ is $\quad-$ 'ipi $\lambda \quad-\mathrm{k} \quad-\mathrm{qa}^{\prime}$

LOC -take along -out of -in the house [M] -FUT -3 .SUB

'He will pull (the slave) out of the house.'

c. papaatah

[R] -pa -atah

SUF- to potlatch -ready to, try to get [R]

'ready to potlatch'

d. ?u?u?utah

[R]- [R]- $\mathrm{pu}$-atah

DIST-SUF- REF -ready to, try to get [R]

'whaling here and there'

We will now move on to examine how polysynthesis and incorporation interact in the language.

\subsection{Polysynthesis and Incorporation}

Incorporation of various constituents is a common concomitant of polysynthesis in the morphology of a number of languages (Gerdts 1988). It is often combined with polysynthesis to form a single morphological type, contrasted with isolating, agglutinative and fusional, but Comrie (1989:45) is careful to distinguish the two:

Although these two terms [i.e., polysynthesis and incorporation] are sometimes used interchangeably, it is possible and advisable to make a distinction between them. Incorporation refers to the possibility of taking a number of lexical morphemes and combining them together into a single word. Polysynthesis, however, refers simply to the fact that, in a language of this type, it is possible to combine a large number of morphemes, be they lexical or grammatical, into a 
single word. We thus see that incorporation is a special case of polysynthesis.

This observation would seem to suggest that where there is incorporation there will necessarily be polysynthesis and, in this respect, Nuuchahnulth bears all of the expected attributes of such a system, including the movement of (some portion of) the object into the verb. Syntactically, the language is basically verb-initial, with some variation in the order of subject and object arguments and other elements. Pronominal reference is marked on the verb by members of a number of alternative paradigms, although in some cases of the 3rd person there is no overt marking. Incorporation of an external element, typically root + derivational affixes, from the direct object into the verb is not uncommon, as shown in (3b).

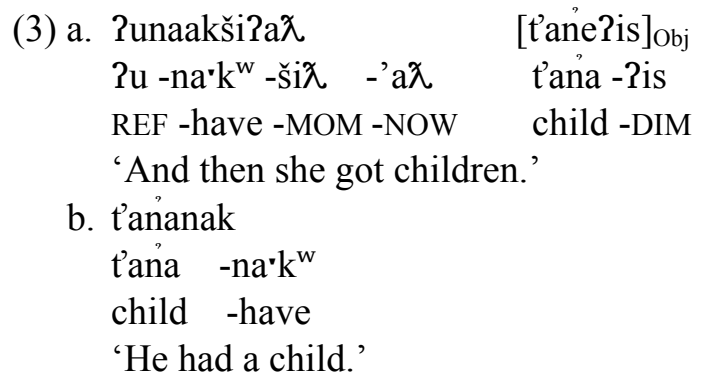

Mithun (1984) provides examples of Nuuchahnulth as an incorporating language, but fails to recognise the existence of a necessary neutral base to which suffixes may be attached, just in case there is no incorporation. Incorporation is never obligatory and appears to have a certain discourse-based force in the grammar. By 'neutral' I mean that such a base makes no obvious contribution, either in subcategorisation or semantics, to the final output, serving only as a referential base, substituting for an incorporated object. This would predict that this base should never occur without some 
derivational suffix that acts as the predicator. Compare the examples in (4a) and (4b), where this base, $? u$, occurs in the first example (4a), but not in the incorporated form in (4b).
(4) a. Punaakwe?in

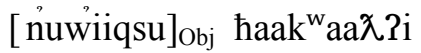
?u - nark $^{\mathrm{w}}$-wer?in
nuwiiqsu
haak $^{\mathrm{w}}$ aa $\chi \quad=\mathrm{i}^{\mathrm{r}}$
REF-have -3.QUOT father
young woman $=\mathrm{DEF}$
'The girl had a father.'
b. nuwicnah?apikin
nuwiiqsu-na’h-'ap -ik -in
yaa
naỷaqak?i
father -seek -CAUS -FUT -1P.IND
yaa
naỷaqak $=$ ? $\mathrm{i}$.
'We'll have that baby look for his father.'

Greenlandic, which is typologically quite similar in terms of its use of polysynthesis and incorporation, exhibits a neutral base also, as noted by Fortescue (1984:83):

With qar ['have'] the possibility of a corresponding nonincorporating construction exists using 'empty' stem $p i$ - plus that affix, the 'object' appearing in the instrumental case externally.

He provides the following examples (ibid) (where -nik indicates the instrumental case):

(5) a. ikinngutiqarpuq

'He has a friend/friends.'

b. ikinngutinik piqarpuq

'He has some friends.'

Thus, for both Nuuchahnulth and Greenlandic, incorporation is optional syntactically, and applies only to objectys since it will always be possible to make use of the so-called referential base, $? u$, 
in Nuuchahnulth, or $p i$ in Greenlandic, with derivational suffixes, instead of incorporating an overt object. In fact, under certain conditions, such as potential extraction from a coordinate structure, incorporation is actually prohibited in Nuuchahnulth (see Stonham 2004). Investigating the exact motivation for incorporation would take us well beyond the scope of this paper and so I will restrict the investigation to the hows rather than the whys of incorporation here.

\section{Numerals}

The study of numerals and their place in the grammar of natural languages has long been viewed as an area of special interest for those concerned with issues of language (see, for example, Hurford 1987, 2003). The Nuuchahnulth number system is fairly complex, although relatively transparent in terms of its structural elements. Numbers from 'one' to 'five' are simplex (6a), while those from 'six' to 'nine' are composed of two elements, the roots for either 'one' or 'two' together with the suffixes $-p u$ 'more than' and $-k^{w} a$ t 'less than' (6b), giving us:

(6)

$\begin{array}{ll}\text { a. cawaa(k) } & \text { 'one' } \\ \text { Paða } & \text { 'two' } \\ \text { qačca } & \text { 'three' } \\ \text { muu } & \text { 'four' } \\ \text { suč̉a } & \text { 'five' }\end{array}$
b. nupu 'six' ?axpu 'seven' ?a入ak ${ }^{\mathrm{w}} \mathrm{a}$ 'eight' cawakk ${ }^{\mathrm{w}}$ ał 'nine'

'Ten' and 'twenty' are morphologically simplex, whereas the higher multiples of 'ten' fall into two categories, either (i) single, morphologically-complex words or (ii) syntactic constructs, without any overlap, at least until 'one hundred'. They are formed by the use of the suffix -iiq '...score' in combination with the syntactic 
construction $P i \check{s} \hbar a y u$ '... and ten'.

\begin{tabular}{|c|c|c|c|}
\hline $\begin{array}{l}\text { (7) a. hayu } \\
\text { caqiic }\end{array}$ & $\begin{array}{l}\text { 'ten' } \\
\text { 'twenty' }\end{array}$ & $\begin{array}{l}\text { b. qačciiqq } \\
\text { qačciiiq ?iš hayu }\end{array}$ & $\begin{array}{l}\text { 'sixty' } \\
\text { 'seventy' }\end{array}$ \\
\hline caqiic ?iš hayu & 'thirty' & muyiiq & 'eighty' \\
\hline ?aXiiq & 'forty' & muyiiq ?iš hayu & 'ninety' \\
\hline Pa入iiq ?iš hayu & 'fifty' & suč̉iiq & 'hundred' \\
\hline
\end{tabular}

Units between the tens are formed by the use of the conjunction Pis 'and' or sometimes Puћ?iš 'and,' with the appropriate unit and decimal indicators, thus:

(8) hayu Piš cawaak hayu ?iš Paג caqiic ?iš qačca ?a入iiq ?iš cawaak

$$
\begin{aligned}
& \text { 'eleven' } \\
& \text { 'twelve' } \\
& \text { 'twenty-three' } \\
& \text { 'forty-one' }
\end{aligned}
$$

Multiples of one hundred are formed in one of two ways: (a) by continuing the use of -iiq '...score' in conjunction with the conjunction $P i s ̌$ or $3 u \hbar ? i s$, or (b) by the use of the appropriate unit combined with a suffix - pit meaning '...times' followed by the form sučiiq 'hundred'. Given the consistency of the former set with the lower numbers we will assume that it is the original pattern and that the alternative system is a calque based on the English number system, i.e., 'two hundred, three hundred,' as shown in (9).

(9) a. hayuuq

hayuuq Piš sučiiq

?axpituuq hayuuq

qaccupituuq hayuuq kiix?in?ath 'there were six hundred Kiihin'

b. $2 a \lambda_{\text {pit }}$ suč̉iiq

qačcupit sučiiq 'two hundred'

'three hundred'

'four hundred'

'two hundred'

'three hundred' 
muupit suč̉iiq

nupupit sučiiq

$2 \mathrm{a}^{\mathrm{a}} \mathrm{k}^{\mathrm{w}}$ ałpit sučiiq 'four hundred'

'six hundred'

'eight hundred'

Multiples of 'one thousand' are formed with the appropriate unit designator followed by a suffix -pit '...times' followed by the borrowed word taawisin 'thousand', and again the structure appears to be calqued from English.
(10) nupit taawisin
'one thousand'
?aגpit taawisin
'two thousand'
Paגpit taawisin Piš muupit suč̉iq 'two thousand four hundred'

There is no overlap between root and suffix within the Nuuchahnulth number system, unlike in other areas of the grammar, where one may encounter morphemes with virtually identical meanings, one of which is a free verb and the other a bound verb, as in the examples in (11).

\begin{tabular}{|c|c|c|c|}
\hline \multirow{7}{*}{ (11) } & Root & Suffix & Meaning \\
\hline & a. na?u' & -pi'yaqh & 'accompany' \\
\hline & b. גawas & -nas?ii & 'approach' \\
\hline & c. maakuk & $-\hbar a^{\prime}$ & 'buy' \\
\hline & d. siqa & -ca'qa & 'cook' \\
\hline & e. qah & -sawix & 'die' \\
\hline & f. ha?uk & -'i’s & 'eat' \\
\hline
\end{tabular}

As one can see from such examples, the free and bound verbs share no physical resemblance, although semantically they perform virtually the same function. In most cases the bound verbs are transitive, although not (11e), for example.

Among the numbers, all are either roots or roots combined with derivational suffixes which perform other tasks elsewhere, with the 
exception of -iiq '...score' which only occurs with the roots for the numbers from 'two' to 'ten'.

\subsection{Classifiers}

Nuuchahnulth employs a fairly large number of bound morphemes which might best be described as classifiers, in the usual sense that they are based on certain characteristics of the object which they describe and to which they are syntactically bound $^{3}$ These classifiers occur in association with a root designating either a number or another quantifier, such as Paya 'many', Panaћ 'few', etc. Examples of classifiers combined with numerals are provided in (12).

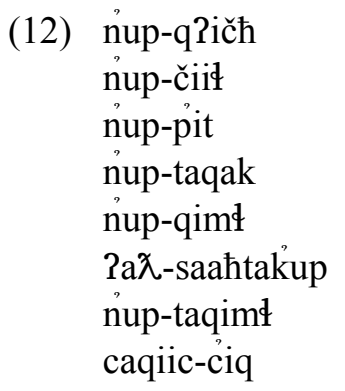

'one year'
'one day'
'one time'
'one unit'
'one chunk'
'two kinds'
'one group, tribe'
'twenty long objects'

Classifiers occur with most nouns, with a few notable exceptions. In addition to the bound classifiers presented above, it is also possible for certain free forms to behave as mensural classifiers, such as the form tapqimt 'bale' in (13g) below. This suggests that the classifier system may be somewhat open and capable of extension should the need arise.

3 For a more detailed discussion of classifiers in Nuuchahnulth, see Stonham (2004). With respect to the specific classifier assigned to each noun, see Stonham (2005)'s dictionary of Nuuchahnulth. 
The distribution of classifiers with respect to complex numbers will be an important factor in the analysis of the syntax of numbers, to be discussed in the following section. Numerals may occur alone with pronominal force (13a), with a noun (13b), with a classifier with pronominal force (13c), with a classifier and noun (13d), as a complex number with noun (13e), as a complex number with classifier (13f) or with a freestanding classifier and noun (13g).

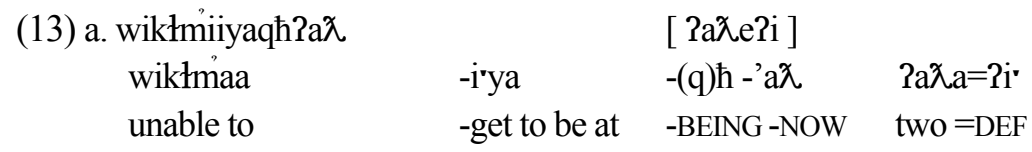
'The two of them could not lift him up.'

b. ?uyu?ałwe?in $\quad \mathrm{k}^{\mathrm{w}}$ atyaat [ ?a入a haathaak ${ }^{\mathrm{w} a}$.]

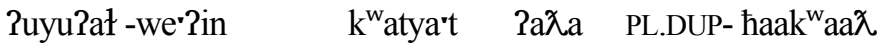
notice -3.QUOT Kwatyat two PL- girl 'Kwatyat caught sight of two girls.'

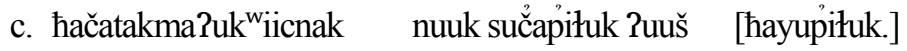

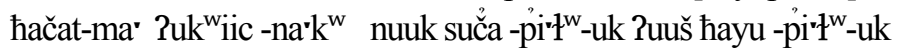
all -3s.IND one's own-have song five-CLS-POSS someten-CLS-POSS 'Everyone has his own songs; some have five, (some) ten.'

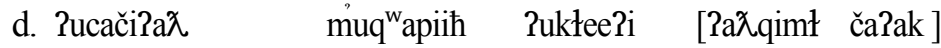

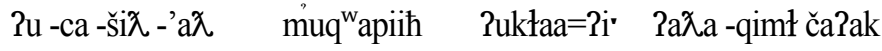
REF-go to-MOM-NOW Burned-around name $=\mathrm{DEF}$ two -CLS island 'They went to the two islands named Burned-about.'

e. Pu?iis?apsi [hayuuq Riš suč̉ii $\chi^{\prime}$ isał.]

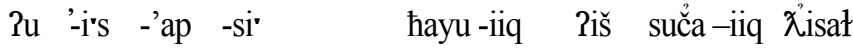
REF-consume-CAUS-1S.ABS ten-score and five-score blanket 'I let them consume fifteen score blankets.'

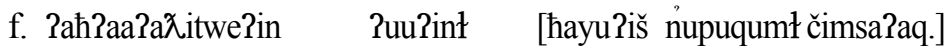
Paћ?aa?a入-(m)it -we'?in ?u -'int hayu ?iš nupu-qimł čimsa?aq and then -PAST -3.QUOT REF -distribute [L] ten and six -CLS bearskin 'And then he distributed sixteen bearskins.'

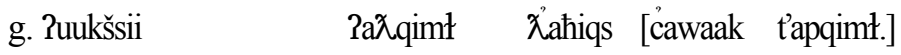




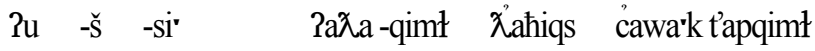

$$
\begin{aligned}
& \text { REF -ask for-1s.ABS two -CLS box one bale } \\
& \text { 'I demanded two boxes (with) each bale.' }
\end{aligned}
$$

These examples will provide us with the empirical basis for describing the syntactic structure of numerals in the following section.

\section{The Syntactic Structure of Numerals}

In this section we will investigate the possible structures involved in phrases containing numerals. Numerals occur along with the head nouns with which they agree within the object phrase, as in forms such as those in the examples in (14).

$$
\begin{aligned}
& \text { (14) a. Paanasa citkk }{ }^{\mathrm{w} i s c u} \text { [ ćawaak t'ane?is] } \\
& \text { only wriggle out one child-DIM } \\
& \text { 'Only one child wriggled out.' } \\
& \text { b. Puyu?ałwe?in } \mathrm{k}^{\mathrm{w}} \text { atyaat [?a入a haathaak }{ }^{\mathrm{w}} \mathrm{a} \chi \text { ] } \\
& \text { catch sight of Kwatyat two young women } \\
& \text { 'Kwatyat caught sight of two girls.' }
\end{aligned}
$$

These examples suggest that the structure of the NP containing a numeral plus noun is something like that in (15).

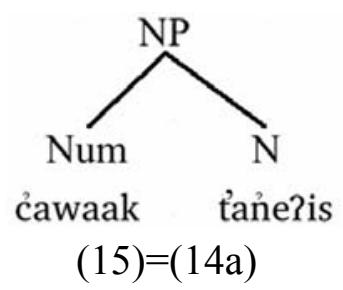

But what about the more complex cases of NPs containing modifiers 
along with numerals? The examples in (16) provide instances of the kinds of combinations encountered:

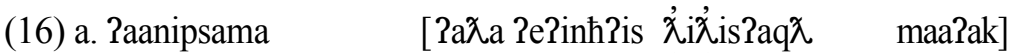

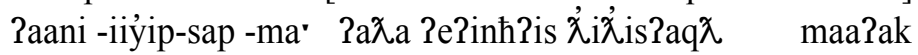

$$
\begin{aligned}
& \text { really -get-CAUS-3.IND two small white-insidegraywhale } \\
& \text { 'All he got were two small white-fleshed gray whales.' } \\
& \text { b. Puhtin [?aגa yaqs lu?uk] }
\end{aligned}
$$

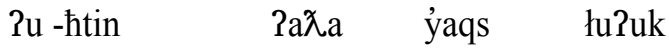

$$
\begin{aligned}
& \text { REF -made of two long boards }
\end{aligned}
$$

Such examples indicate that the rest of the NP follows the numeral in the unmarked case, including any modifiers. This calls for a modification to the structure in (15) above, with the numeral in a specifier position (17). ${ }^{4}$

(17)

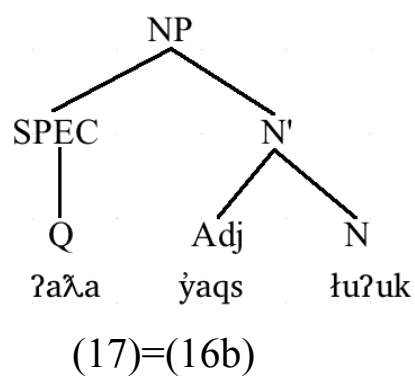

\footnotetext{
${ }^{4}$ The focus here is on the conjoining of parts of numerals to form a whole number. For further discussion of the properties of noun coordination in Nuuchahnulth, see Stonham (2004). Here and elsewhere I will include only those nodes in the trees that are directly relevant to the exposition, leaving out others, such as the AP node in (17) for the sake of expository simplicity. Additionally, I project syntactic phrases such as DP, QP, ClP, etc. only when they are warranted by the presence of determiners, quantifiers, classifiers, etc. in the phrase.
} 
Until this point, the examples we have encountered have been of simplex numbers combining with a noun and possibly a modifier, but we should now consider the consequences of complex numbers arising in this situation. Examine the data in (18).
(18) a. [[muuyiiq 2iš hayu Piš suč̉a $]_{\mathrm{QP}}$ taana $]_{\mathrm{NP}}$ four-score and ten and five dollar '95 dollars'

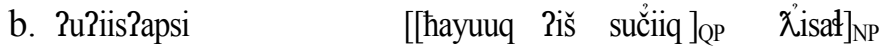

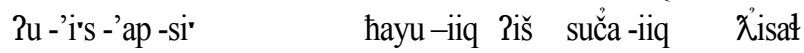 REF -consume-CAUS-1S.ABS ten-score and five-score blanket 'I let them consume 300 blankets.'

In such cases, the entire QP, containing the complex numeral, surfaces before the head noun, as in (19).

(19)

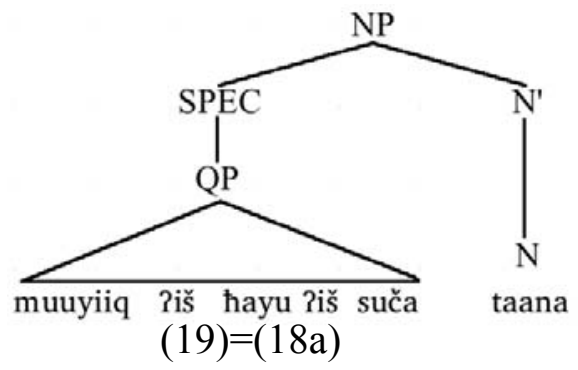

\subsection{Classifier Position}

The examples above should be sufficient to demonstrate the typical syntactic structure involving numerals, that is, the place of the numeral, whether simplex or complex, within the phrase. When 
a classifier is also involved, its position is between numeral and noun, as exemplified in (13c) and (13d) above.

If classifiers occur between numerals and nouns, this militates for a somewhat different structure for the object phrase as a whole, one in which numerals take classifiers as complements. Numerals and classifiers are intimately bound in any language that employs them (cf. Matthews \& Yip 1994 for Cantonese, Sohn 1999 for Korean, etc.) and there is no reason not to expect the same in Nuuchahnulth. The optimal means to accomplish this is by including the classifier within a unit containing the numeral. The most obvious way to do so is to propose a quantifier phrase, QP, containing a classifier phrase, ClP, as its complement. Classifiers, which delimit the class of possible nouns that may appear within their scope, would then take the noun as a complement. This structure for the quantifier phrase and its components is presented in (20).

(20)

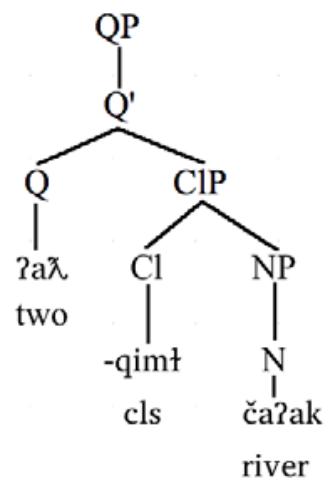

But do we really need a classifier phrase (ClP)? Because classifiers delimit the class of possible nouns as head of the NP, the classifier should have scope over the NP. The best way to achieve this is to place the NP in a complement position to the classifier (Abney 1987). In the majority of cases in Nuuchahnulth, theclassifier is a 
bound element and must therefore move, via some form of merger, to join with the quantifier in Q. However, in the case of certain mensural classifiers referring to containers, the form is freestanding and will not combine with the numeral but will remain in $\mathrm{Cl}$, for example t'apqimt 'bale (of $\mathrm{X}$ )' from (14g). This would require a structure such as that in (21).

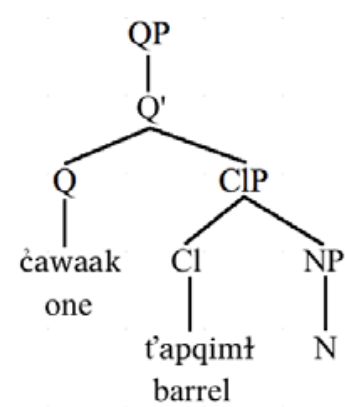

In this case there is no merger, since neither form is bound and therefore the $\mathrm{Q}$ and the $\mathrm{Cl}$ remain in their respective head positions. This empirical evidence supports the positing of a classifier phrase, ClP, between QP and NP. It further bolsters the need for the independence of ClP from QP, given the possibility of separate, freestanding classifiers such as tapqimt 'bale'.

\subsection{Coordination and its Role in the QP}

Coordination is used in several ways within the Nuuchahnulth number system and it is an important element of many numerals. First, it conjoins units to tens, and scores with tens and units, as in (22).

(22) a. hišimỷuupaðsi quamaa?akqas ?uwaatin caqiic ?iš hayu hišimỷuup-'a $\chi$-si' q⿳ama'-'ak-qa's ?uwaatin caqic ?iš hayu assemble-NOW -1S.ABSthus -POSS-1S.SUB relatives twenty and ten 
'I gathered together all my relatives, 30 of them.'

b. Taxpuuq Tiš hayu Riš muu 'one hundred and fifty-four'

In addition, it can be found to conjoin coordinate NPs which contain numbers.

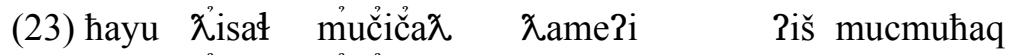

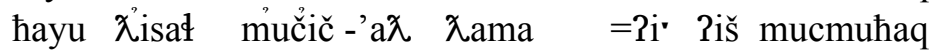
ten blanket clothed-now house post $=$ DEF and bearskin 'The post was clothed with ten blankets and a bearskin.'

This fact suggests the need for a more articulated shape for the quantifier phrase containing a complex numeral. The idea here is that the phrase acting as numeral is basically a quantifier phrase in which the head is the numeral that delimits the possible range of numbers, much as we talk about units, tens, hundreds, etc., it is important to bear in mind that the use of conjunctions in complex numerals is not the same as the use of the same conjunctions within coordinate structures. Coordinate structures allow the inversion of the elements of the different branches with no direct influence on the interpretation other than a temporal effect, as shown in (24). Reversing the order of elements within a numeral, on the other hand, has serious consequences for the interpretation of the resulting form, as illustrated by the example from French in (25).

a.

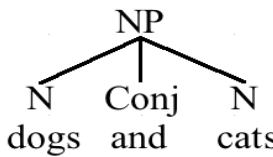

b.

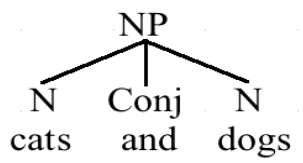


96 On the Inherent Complexity of Language

(25) French:

a.

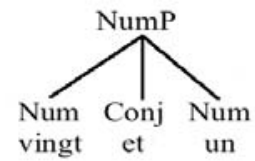

b. $\left.\left.\right|_{\text {un }} ^{\text {NumP Conj }}\right|_{\text {et }} ^{\text {Numpt }}$

To summarize, the Quantifier Phrase, QP, may consist of a specifier (SPEC), a head (Q), and a complement. The complement of $\mathrm{Q}$ will be phrasal, either (i) another QP to allow for the construction of complex numerals, (ii) a classifier phrase to account for the presence of a classifier, or (iii) a noun phrase (NP). In the simplest case the QP may consist solely of a $\mathrm{Q}$ acting as a pronominal, e.g., 'two'.

(26) a.

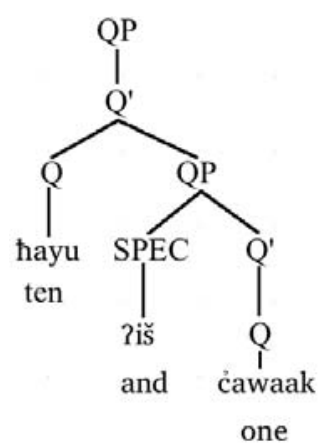

b.

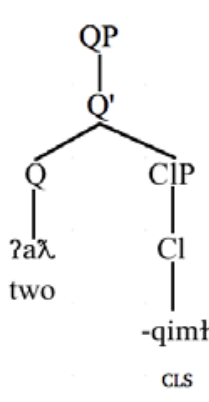

c.

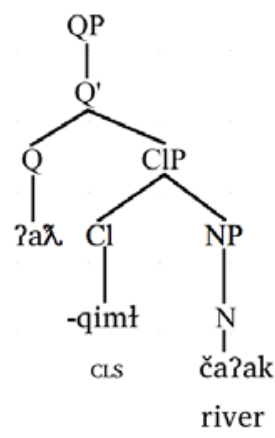

The phrase structure rules responsible for these various realizations of the QP are provided in (27). 


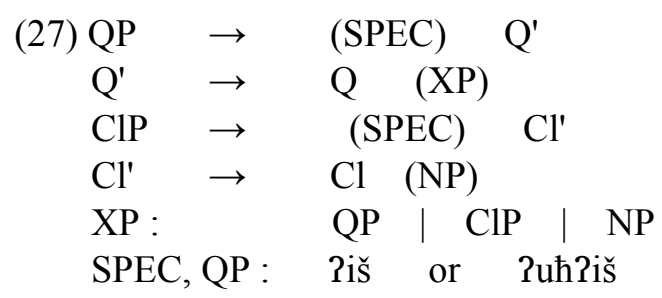

Should the number involved be complex, then we must have some way to distinguish between the highest head and the 'complement-head' members of the number, so that only the highest head may be subject to incorporation, along the lines of (28). In the case of Nuuchahnulth, the largest numeric domain comes first in the majority of cases, but not always (see 9b, for example).

Compare this with examples from German, e.g., ein und zwanzig or French, e.g. vingt-et-un, both meaning 'twenty-one', but where the former involves a small-to-large ordering and the latter a largeto-small. Clearly both possibilities are available, and employed, typologically.

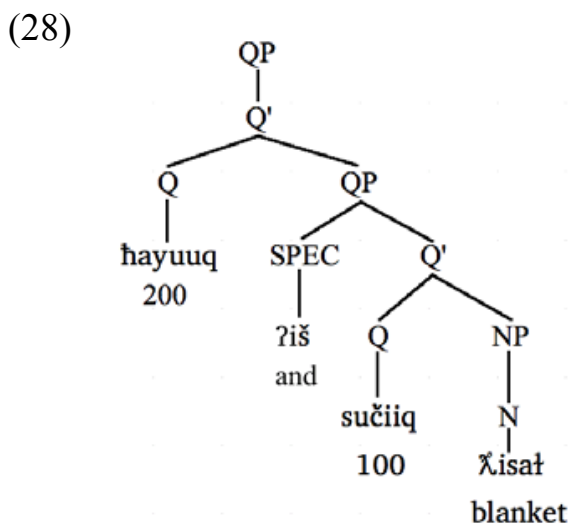


We now move on to the focal issue of this paper: how the structure of the QP interacts with the process of incorporation in Nuuchahnulth.

\section{Numeral Incorporation}

The numeral system as described above is already quite complex, but the fact that Nuuchahnulth allows incorporation of various elements from the object presents yet a further and more challenging level of complexity which we shall now explore. ${ }^{5}$ This is interesting because of the interaction of numerals with incorporation, and this will be the focus of the remainder of this paper. The crucial example is presented in (29).

$$
\begin{aligned}
& \text { (29) hayuu } \text { }_{\mathrm{i}} \text { isuksi } \quad\left[\mathrm{e}_{\mathrm{i}} \text { Piš } \quad \text { sučiiq taana }\right] \\
& \text { hayu-iiq -'i’s -uk -si' Tiš suča-iiq taana } \\
& \text { ten -score-consume-NOM-1S.ABS and five-score dollar } \\
& \text { 'I spent three hundred dollars on him' }
\end{aligned}
$$

Note that in this example, there is a complex numeral which is separated into two parts, one part combined with the verb, the other part remaining in its original site, preceded by the coordinator, $2 i \check{s}$. Such examples pose an interesting problem for lexical treatments of incorporation, since the two parts of what would appear to be a single, complex numeral $(=300)$ are located at a distance from one another. This is the usual manner in which incorporation is effected with such elements, and it is always the first element of the complex numeral which is incorporated.

Under these conditions, we can now explain how incorporation

\footnotetext{
${ }^{5}$ For a fuller exposition of incorporation in Nuuchahnulth, see Stonham (2004). For an alternative view, cf. Waldie (2005), Stonham (Ms).
} 
works in these cases. Firstly, it operates on the highest head of the object, whether this is an NP or a QP. If it is an NP, then the N is incorporated, as one would expect. But if the noun object is actually within a quantifier phrase, then the head of the QP, which is higher in the structure, is the target of incorporation, not the head noun.

The following examples demonstrate that this process is not strictly limited to numerals, although they pose the most interesting challenge for this process, since the parts of a number may be separated from each other, whereas for other quantifiers that are only single words, such as Paya 'many,' the entire word may move, as in (30b).

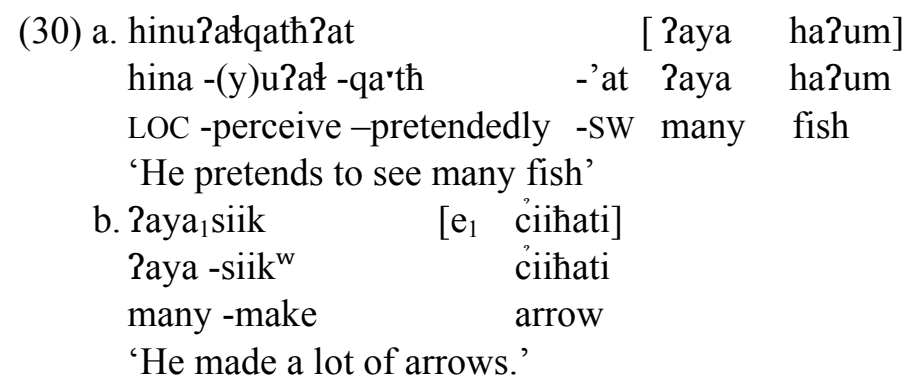

As can be seen from these examples, the quantifier Paya 'many' can appear in a similar position to the numerals, preceding the noun, or it can be incorporated into the verb, just as the head numeral can. Also similarly, when it occurs in conjunction with a noun or noun phrase, it is always Paya which is incorporated, not the noun.

All of this suggests that, like the numbers, other quantifiers occur within a domain containing both the quantifiers and the NP, and that incorporation is sensitive to the head of the larger phrase, whether it be NP or QP, within the sentence. In the case of numerals, it would seem that the best analysis of the empirical facts is to consider the quantifier phrase to contain the noun phrase and to determine the range of possible noun complements based on the classifier 
employed.

Under such an analysis, cases such as (30b) above must be derived by means of a long-distance dependency between the main verb and the direct object, along the lines of (31a) and (31b). (31a) shows the underlying structure of the main verb and its object. In (31b), the quantifier Paya moves via head movement and adjoins to the left of the verb, leaving the noun ciihati 'arrow' stranded in situ.

(31)

a.

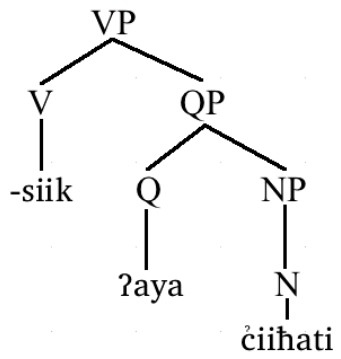

b.

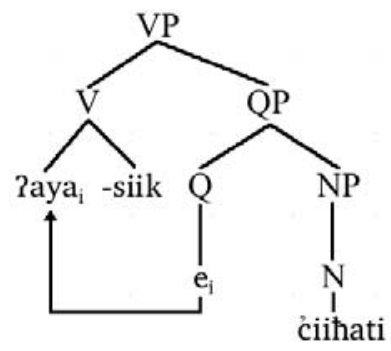

$$
(31 \mathrm{a})=(30 \mathrm{~b})
$$

This example demonstrates the long-distance nature of the process. Clearly, more complex examples will present even greater complexities, as shown by the case in (32). Important to note here is the fact that the movement in this example occurs across an intervening subject argument which interrupts the verb and its object.

(32) a. caqiicqimł $\}_{i}$ ayii?atma $\quad \chi$ apisim [ $\mathrm{e}_{\mathrm{i}}$ Riš sučaqumł taana] caqiic-qimł-ayii -?at-ma $\chi$ apisim Piš suča-qimł taana twenty-CLS -give-SW -3.INDRacoon and five -CLS dollar 'Racoon was given twenty-five dollars.' 
b.

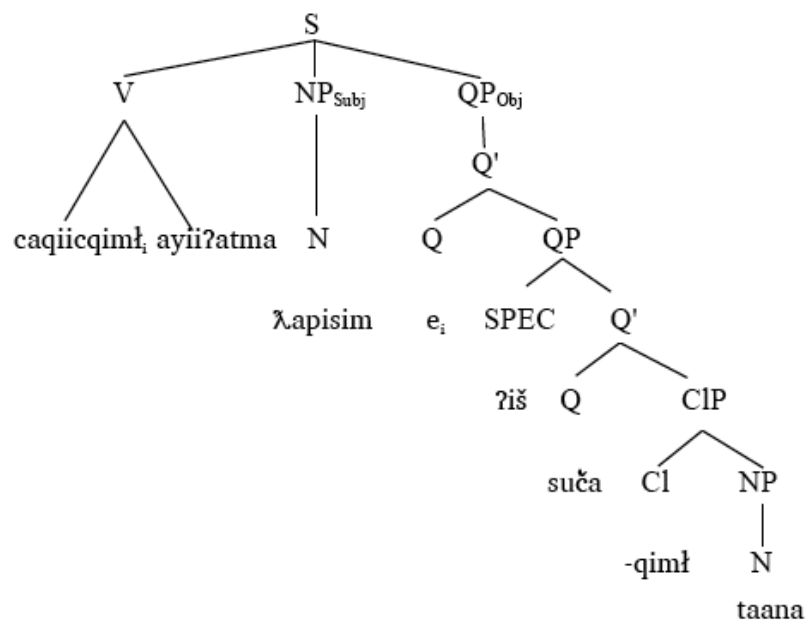

In this case we can see that the highest Q within the QP is merged with the main verb to give caqiicqimlayii?atma 'to be given twenty.' The rest of the QP is in its expected object position, following the subject, Xapisim 'Racoon.' Examples of this type are the strongest empirical evidence for the long-distance nature of numeral incorporation in Nuuchahnulth.

\section{Conclusion}

In conclusion, the proposal here maintains that it is necessary to subsume the object NP within a larger QP when it is associated with any quantifier, and that in such a situation incorporation must necessarily involve syntactic movement from the position of head of QP. Furthermore, classifiers must be taken into account, as part of a classifier phrase, ClP, between the QP and the NP. This then suggests that incorporation demands a syntactic movement or its equivalent, rather than a lexical rule generating the object and its 
related elements in situ. The result of numeral incorporation in Nuuchahnulth is a discontinuous element, part of which is found combined with the main verb, and the remainder of which is associated with the syntactic object of that clause.

The interaction of incorporation with the numeral system of Nuuchahnulth highlights the extent to which languages can vary and the complexities that linguists must consider in constructing theories of language. This case clearly demonstrates the limits to which learnability can extend as well.

Typologically, Nuuchahnulth stands near the extreme end of both polysynthesis and incorporation and must be considered carefully when addressing issues concerning the relationship between words and sentences. Languages such as this provide important evidence of long distance relationships among syntactic elements.

The phenomena involved here are rare in the languages of the world, and their combination even rarer, since it requires a language to have a confluence of several quite special properties: object incorporation, syntactically complex numerals, and a $\mathrm{QP} / \mathrm{ClP} / \mathrm{NP}$ alternation for syntactic phrases. It would be interesting to examine other similar cases to see if they behave in a similar fashion, should such cases be discovered.

\section{References}

Abney, S. 1987. The English Noun Phrase and its Sentential Aspect. Ph.D. Dissertation. Cambridge: Cambridge University Press.

Baker, M. 1996. The Polysynthesis Parameter. Oxford: Oxford University Press.

Comrie, B. 1989. Language Universals and Linguistic Typology. Oxford: Blackwell.

Fortescue, M. 1984. Greenlandic. London: Croom Helm. 
Gerdts, B. 1988. Incorporation. In A. Spencer \& A. Zwicky (eds), Handbook of Morphology 84-100. Oxford: Blackwell.

Hurford, R. 1987. Language and Number: The Emergence of a Cognitive System. Oxford: Basil Blackwell.

. 2003. The Interaction between Numerals and Nouns. In F. Plank (ed.), Noun Phrase Structure in the Languages of Europe 561-620. Berlin: Walter de Gruyter.

Kim, E. 2003. Theoretical Issues in Nuu-chah-nulth Phonology and Morphology. Ph.D. Dissertation. Vancouver: University of British Columbia

Matthews, S \& V. Yip. 1994. Cantonese: A Comprehensive Grammar. New York: Routledge.

Mithun, M. 1984. The Evolution of Noun Incorporation. Language 60.4, 847-894.

Sapir, E. n.d. Fieldnotes on Nootka. Ms. Philadelphia: Boas Collection American Philosophical Society.

Sapir, E. \& M. Swadesh. 1939. Nootka Texts, Tales and Ethnological Narratives. Baltimore, MD: Linguistic Society of America.

. 1955. Native Accounts of Nootka Ethnography. Bloomington, IN: Indiana University.

Sohn, H. 1999. The Korean Language. Cambridge: Cambridge University Press.

Stonham, J. 1999. Tsishaath Nootka Phonetics and Phonology. Munich: Lincom Europa.

. 2004. Linguistic Theory and Complex Words. London: Palgrave Macmillan.

.2005. Dictionary of the Nuuchahnulth Language of Vancouver Island.

New York: Edwin Mellen Press.

Stonham, John. Ms. Verb Argument Composition in Nuuchahnulth: A Special Case of Denominal Verb Formation. Under Review International Journal of American Linguistics 8, 125-245.

Waldie, J. 2004. Nuu-chah-nulth Denominal Verbs. M.A. Thesis. Victoria: University of Victoria 